FOCUS: Journal of International Business

Volume 4, Issue 2, July-December 2017, pp. 44-58

doi: 10.17492/focus.v4i02.11686

\title{
The Rational Expectations in Globalisation: Gauged Globalisation
}

\author{
Binish Qadri*, Mudaser Ahad Bhat** and Aamir Jamal***
}

\begin{abstract}
The forward march of globalisation seems muted since the financial crisis of 2008. Literature shows globalisation entering a more cautious and regulated phase. We're creating a "a new gated globalisation" argues Greg (2013). According to him, 'walls have been constructed' to obstruct the free flow of trade and money. However, such walls have "gates" that countries can open or close as they please. The present paper argues that Greg's 'gated globalisation' has become 'gauged globalisation' because only those gates are opened from which all benefits can be rationally forecasted and then gauged properly by participating players. For better and comprehensive understanding of globalisation we need a good interface of Internalisation, Liberalisation and Universalisation. Through spread and backwash effects, the present paper explains the interface between globalisation and technology and examines the viewpoints regarding the two first at national level and then at global level. The discussion shows that globalisation and technology is not bad; in fact, the bad view is generated by the wrong understanding of the interface between the two.
\end{abstract}

Keywords: Globalisation; Gated globalisation; Gauged globalisation; Internalisation, Liberalisation; Universalisation; Technology.

\subsection{Introduction}

The present era globalisation has manifested itself into its various facets and economic globalisation being one of them. Although, in modern world, economic globalisation continues to experience shocks due to one reason or the other, but other types of globalisation like political globalisation, cultural and digital globalisation are advancing at a rapid rate. Globalisation, thus, still continues to be the dynamic force in

\footnotetext{
*Corresponding author; Research Scholar, Department of Economics, Central University of Kashmir, Jammu and Kashmir, India. (Email id: qadribinish@gmail.com)

**Research Scholar, Department of Economics, Central University of Kashmir, Jammu and Kashmir, India. (Email id: mudaserahadbhat1990@gmail.com)

***Research Scholar, Department of Economics, Central University of Kashmir, Jammu and Kashmir, India. (Email id: aamirjamal06@gmail.com)
} 
modern times. This is because all types of globalisation are inter-related to each other in many ways that it becomes very difficult to distinguish between them. That is to say that at one point of time, one form of globalisation outweighs the other form, and at the other point of time another form outweighs the other form but overall globalisation is always positive and the basic form of globalisation continues to be the same as it was decades ago. The present paper argues that past globalisation continues in its present form with some new realities and new dimensions. Thus the main objectives of the study are to understand globalisation comprehensively; and to argue that past globalisation continues in its present form.

\subsection{Methodology}

An ex-ante measure and subjective definition of globalisation has been used, namely interaction among Internalisation, Liberalisation and Universalisation (ILU) measures. The purpose is to discuss whether the old globalisation continues in its present form or not. In this context, we will not address increasing trade openness and FDI; these are ex-post (actual) proposals where some aspects are difficult to treat in a theoretical paper like the present one. An important limitation of the subsequent analysis is that the ex-ante proposals may be announced but not implemented or implemented but not effective, which actually happens in the real world and accordingly we think that globalisation is in retreat. However, in the present study, we assume that all ex-ante proposals are rationally announced and effectively implemented in order to prove our stand.

\subsection{Literature Review}

In order to fulfil the objectives of our study, the literature review is divided in two parts. The first part is examining the evolution and definitions of globalisation in order to understand it comprehensively while the second part of the literature review is examining the existing literature which deals with the debate whether globalisation is in retreat process or not; and how globalisation and technology are interrelated.

\subsection{Evolution of the concept of globalisation}

The word globalisation as a process first appeared in the English language in 1959 and entered a dictionary two years later (Schreiter, 1997; Webster, 1961) and the notions of globalisation as sine-qua-non began to circulate in the 1980s (Robertson, 1983). Globalisation refers to all those processes by which the people of the world are incorporated into a single world society, global society (Albrow and King,1990). It can 
be defined as the intensification of worldwide social relations which link distant localities in such a way that local happenings and decision making are shaped by events and decision making occurring many miles away and vice versa (Giddens,1990).The globalisation attributes include the internationalisation of production, the new international division of labour, new migratory movements from South to North, the new competitive environment that generates these processes, and the internationalising of the state, making states into agencies of the global world (Cox,1994). However, globalisation is qualitatively different from internationalisation as it involves not merely the geographical extension of economic activity across national frontiers but also the functional integration of such internationally dispersed activities (Dicken,1998).The process of globalisation simultaneously show two faces. The former entails the extension outwards of a particular culture to its limit, the globe. Heterogeneous cultures become incorporated and integrated into a dominant culture which eventually covers the whole world. The latter points to the compression of cultures (Featherstone, 1995). There is a process of cultural mixing or hybridization across locations and identities (Appadurai, 1996). Globalisation can also be defined in terms of material set of practices drawn from the business world blended with a neo-liberal market ideology (Currie and Newson, 1998).

Globalisation is political, technical, cultural, as well as economic. It is 'new' and 'revolutionary' and is mainly due to the 'massive increase' in financial foreign exchange transactions which has been facilitated by dramatic improvement in communications technology, especially electronic interchange facilitated by personal computers (Giddens, 1999). This resulted in time-space compression (Harvey, 1989), deterritorialization or the growth of supra territorial relations between people (Scholte, 2000) and the integration of the world economy (Gilpin, 2001). It led to shrinking of the world, the shortening of distances, and the closeness of things. It allows the increased interaction of any person on one part of the world to someone found on the other side of the world, in order to benefit.The world-wide interconnectedness between nation-states becomes supplemented by globalisation as a process in which basic social arrangements become disembedded from their spatial context (mainly the nation-state) due to the acceleration, massification, flexibility, diffusion and expansion of transnational flows of people, products, finance, images and information (Beerkens, 2004). It would be a mistake to regard globalisation as a kind of imperialism. Globalisation is a far larger and more complex process than that. Globalisation involves spreading of ideas, practices and technologies, and it is little more than internationalization, universalisation and market liberalisation. Globalisation, in the sense of connectivity to the global economic and cultural life brings with it a different order than what it was before. 
While examining the first part, we come to know that much if not most existing analysis of globalisation is flawed because it is redundant failing to generate new understanding that is not attainable with other concepts (Scholte, 2007). The term globalisation has been loosely defined. In fact, it is poorly conceptualised. Moreover, these definitions are in some ways related and to some extent overlapping, but their emphases are substantially different. Knowledge of globalisation depends to a great extent on how the word is defined. The dissection of globalisation must include a careful and critical examination of the term itself. Four main definitions of globalisation have led into cul-de-sac: globalisation as internationalisation; globalisation as liberalisation; globalisation as universalisation; and globalisation as westernisation. Contemporary history have almost invariably defined the term in one or several of these four redundant ways (Scholte, 2007).The present paper therefore highlights the interaction of Internalisation, Liberalisation and Universalisation( ILU) as sine-qua-non and defines globalisation in terms of ILU process and not just purely internalisation or liberalisation or universalisation. Further, the literature review doesn't throw light on internalisation as one of the main part of globalisation .No instance has been found where globalisation has been described the way present paper does. The present paper attempted to give a definition of its own on globalisation so as to understand globalisation comprehensively. Globalisation is "a process fuelled by and resulting in Internalisation, Liberalisation and Universalisation (ILU) thereby leading to the creation of global networks and global society".

\subsection{Globalisation and Technology}

Globalisation and technology are two drivers that have always been latent fault lines. They have created both winners as well as losers. The economic inequalities we see today is a result of how we have chosen to manage the two (Reeves and Harnoss, 2016). Rather than signalling the death of globalisation, the decline in the traditional metrics signals the birth of a radical new phase of globalisation-one that rebalances geopolitics with geo-economics (Bhattacharya, Bürkner and Bijapurkar, 2016). Tremendous advances have been made by large segments of the world population in this age of globalisation. Yet, there is a fear that globalisation is exacerbating inequality, and perhaps even worsening the lot of the poor by eroding their incomes, increasing their vulnerability, and adding to their disempowerment. This fear may not be universal, but it does play a role in the public perception that cannot be ignored (World Bank, 2000). More state intervention in the flow of money and goods, more regionalisation of trade as countries gravitate towards likeminded neighbours, and more friction as national selfinterest wins out over international cooperation. Together, all this amounts to a new, 
gated kind of globalisation. Governments increasingly pick and choose whom they trade with, what sort of capital they welcome and how much freedom they allow [firms] for doing business abroad (Greg, 2013). Globalisation isn't what it used to be. Times have changed. Globalisation hasn't been repealed, but it has entered a more cautious and regulated phase. Globalisation reflects three basic forces: lower transportation costs (containerization, air freight); cheaper communications ; and favourable government policies (Samuelson, 2013).

The second part of literature review point towards the new phase of globalisation. Some call it 'gated globalisation' (Greg, 2013) and some call it radical phase (Bhattacharya, Bürkner and Bijapurkar, 2016). However ,the present paper argues that we have entered in a 'gauged globalisation' phase because only those gates are opened from which all benefits can be rationally forecasted and then gauged properly by participating players. It is on the basis of the interaction between Internalisation, Liberalisation and Universalisation (ILU) that the countries decide which gate to open. The term gauged globalisation, based on rational expectations, is author's own term. The theory of rational expectations was first proposed by John F. Muth of Indiana University in the early 1960s (Muth, 1961) and later became influential when it was used by Robert Lucas. The influences between expectations and outcomes flow both ways. In forming their expectations, people try to forecast what will actually happen. They have strong incentives to use forecasting rules that work well enough because higher "profits" accrue to the one who acts on the basis of better forecasts. And when people have to forecast a particular price over and over again, they tend to adjust their forecasting rules to eliminate avoidable errors. Thus, there is continual feedback from past outcomes to current expectations.

The rational expectations hypothesis has been used to support some strong conclusions about economic policymaking. An example is the policy ineffectiveness proposition developed by Sargent and Wallace (1975).The gauged globalisation based on rational expectation makes our argument strong and rejects the retreat globalisation debate. The role of technology and globalisation in growth and development process has been in debate for past many decades. Existing literature, no doubt talks, about the technology and globalisation linkages in that it argues that the economic inequalities we see today is a result of how we have chosen to manage the two. The papers reviewed for the present study didn't discuss the interface of globalisation and technology in the manner present study does. No study so far in the existing literature on globalisation and technology linkages have used the concepts of spread and backwash effects. It is an economic development effect suggested by Swedish economist Gunnar Myrdal (1957) to explain and examine the viewpoints regarding globalisation and technology first at 
national level and then at global level and their role in reducing inequalities. The aim is to arrive at the conclusion that globalisation and technology is not bad. The present paper has attempted to fill this research gap. Through backwash and spread effects the present paper shows the interaction of globalisation and technology and answer the following questions:

- What causes extreme increase or decrease in, within and between the country inequalities?

- What causes bad view about globalisation and technology?

\subsection{Types of Globalisation}

On the basis of ILU process, globalisation can be divided into following types:

(i) Economic: Economic globalisation refers to creation of 'global economy' as a result of growing scale of cross border trade of commodities and services and the exchange of resources.

(ii) Political: Political globalisation refers to the expansion of political activities, decision making and political cooperation across political frontiers so that political activity and decisions in one region of the world impact and get impacted by political activity and decision making in another part of the world. Here the aim is to create 'global polity'.

(iii) Social: Social globalisation pertains to dialogue making and interactions of humans among cultural communities. Here the aim is to create global 'society'.

(iv) Digital: In the past, globalisation was visible mainly in terms of physical goods and exchanges but today we have entered a phase of digital globalisation, defined largely by invisible flows of data and information. Now-a-days, digital flows of data and information generate more economic value than visible flow of physical exchange. Due to digital globalisation, globalisation has become more broad based and inclusive because everyone can participate in digital globalisation. The aim of digital globalisation is to create 'digital global world'. This is the new era of global flows.

(v) Gauged Globalisation: A type of globalisation, based on rational expectations, in which benefits of globalisation can be rationally forecasted and properly gauged on the basis of interaction among Internalisation, Liberalisation and Universalisation (ILU).It is on the basis of this interaction that the countries decide which gate to open. Only those gates are opened from which all benefits can be rationally forecasted and then gauged properly by participating players. 


\subsection{Aim of globalisation}

As a ILU process, the aim of globalisation is to create global world/village. At political level, globalisation creates political village; at economic level, it creates economic village; at social level, it creates social village and social networks and now contemporary globalisation also creates digital village. Thus, finally globalisation arrives at global world/village. Other subordinate aims of globalisation like cutting down costs, bringing increase in efficiency, creation of employment opportunities ,extending help in political and economic decision making etc. lie under the basic aim of globalisation viz. to create global village. Figure 1illustrates this process.

\section{Figure 1: Aim of globalisation}

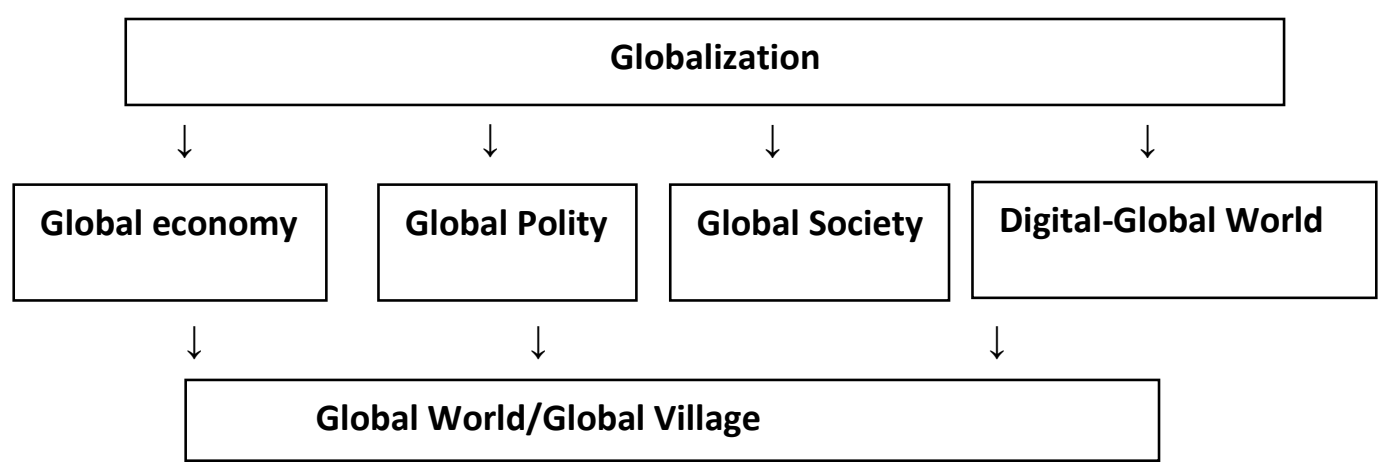

Source: Compiled by author

\subsection{Old globalisation}

During its previous phases, globalisation was about cross-border flow of people, goods and services. Global economic growth and free trade took precedence over politics, and multilateralism over nationalist pressures. In its initial phases globalisation was a pole based globalisation. In fact, pole-based globalisation was a common phenomenon in old globalisation regime in which one or more countries served as an economic pole or a group of countries from different regions of the world formed an economic pole such as Britain and other maritime powers in the late $19^{\text {th }}$ century, the US after World War II, and China in the late 1990s and early 2000s. However, in contemporary times globalisation is not pole based because digital technologies are not dominated by one country (or a few countries) that can leverage their benefits. 


\subsubsection{Features of old globalisation}

- Old globalisation was limited in scope as it was largely confined to economic transactions and exchanges between the countries, political and social aspects were loosely handled by the countries.

- Old globalisation was easy to administer as aim of globalisation was mainly economical in nature and accordingly it was free from multiplicity of goals.

- In old globalisation, countries used to globalise their economies largely to maintain reputation in the eyes of the world rather to avail large economic benefits.

- In old globalisation, the consequences of local events used to have less pronounced global consequences as old globalisation was largely pole based.

- It is very important to note that in old globalisation, stress was mainly on liberalisation and privatisation; internalisation, digitalisation and universalisation processes were missing.

\subsection{Understanding Globalisation as ILU- Gauged Globalisation}

Globalisation as 'internalisation' implies a strategic, coordinated process that seeks to describe the growth in international exchange and interdependence and integrates international policies, programmes and initiatives. Thus in globalised economy, distinct national economies are subsumed and rearticulated into the system by international processes, operations and transactions. Globalisation as 'liberalisation' implies a process in which social, political, cultural, economic and other rights of the people are liberated from government imposed controls, nationally and internationally so that movements within or between the countries become possible with the aim to create borderless world. It thus follows from this definition that local character of globalisation and global character of globalisation are inter-related. Globalisation as 'universalisation' implies a process in which liberated cultures, ideas, customs and practices are spread around the world, thereby creating a social web and a single culture. In simple terms we can write mathematically as:

\section{$\mathrm{G}=\mathrm{f}(\mathrm{I}, \mathrm{L}, \mathrm{U})$}

Separately any of the three cannot provide deep insights into the notions of globalisation. For better and comprehensive understanding of globalisation we need a good interface of the three for a bad interaction among the three processes will create 'gauged globalisation'. Globalisation and its rational expectations influence each other and the understanding of the dynamics of this process is necessary to understand globalisation. This approach to globalisation is termed as gauged globalisation. Thus 
rational expectations make gauged globalisation quite a different animal from past general globalisation because nations have full and accurate information about the future costs and benefits of globalisation. It is important to recognise that this does not imply that participants of globalisation have 'perfect foresight' or that their expectations are always 'correct'. What it does suggest is that agents of globalisation reflect upon past errors and if necessary revise their expectational behaviour so as to eliminate regularities in these errors. So, nations form expectations about costs and benefits of globalisation and then refer them in making decisions about globalisation.

The concept of rational expectations asserts that outcomes do not differ systematically (i.e., regularly) from what people expected them to be. The concept is motivated by Abraham Lincoln's assertion, "You can fool some of the people all of the time, and all of the people some of the time, but you cannot fool all of the people all of the time." (Goodwin, 2005). From the viewpoint of the rational expectations doctrine, Lincoln's statement sets the stage right. It does not deny that people often make forecasting errors, but it does suggest that errors will not persistently occur on one side or the other. Rational expectation theorists believe that people behave in ways that maximize their utility or profits. In modern times Greg's 'gated globalisation' has become 'gauged globalisation' because only those gates are opened from which all benefits can be rationally forecasted and then gauged properly by participating players. A country, say $X$, in which interaction among ILU is good and up to expectations open its gate for such a country, say $\mathrm{Y}$, in which the interaction among ILU is harmonious too because countries rationally forecast that from such a harmonious interaction among ILU they will get greater benefits. Some players think that the interaction among ILU is not good across some countries of the world. As a result these players restricted their globalisation operations with such countries because they feel that their benefits are no longer served in these countries. On the other hand, there are some countries in the present world with which such countries (i.e. countries presuming that their national interests are no longer served in some countries due to disharmonisation of ILU) increase their globalisation operations because they feel that in such countries their national interests could be better served due to good and harmonious interaction of ILU. This indicates that over time direction of globalisation changes on the basis of rational expectations. This is why some people think globalisation is in retreat.

Let us take an example of gauged globalisation. A landlocked country Bhutan has no relations with any of the five permanent members of the UN Security Council because Bhutan rationally forecasts that she will not be able to appropriate diplomatic and other benefits from these five permanent members. On the other hand, only two countries-Bangladesh and India have embassies in Bhutan's capital, Thimpu because the 
country Bhutan is getting diplomatic and other benefits from these two countries. In this way we can say Bhutan has adopted 'gauged globalisation' but all gates of globalisation from all countries of the world, except China, are open for Bhutan. Thus, in strict sense, we can say that actually all gates of globalisation are open across different countries of the world but different countries choose only selective gates so that they can properly gauge the benefits of globalisation. Thus, old globalisation continues in its present form.

\subsection{Globalisation and Technology: A Missing Link between Them}

Countries not only rationally forecast benefits and costs of globalisation but also rationally forecast costs and benefits of technology. If we look from the grass root level then it appears that technology is implicit in the globalisation and vice-versa and accordingly there is an interaction between technology and globalisation. Now finally, countries forecast the costs and benefits of such globalisation-technology interaction through spread and backwash effects respectively. Almost all economists hold the view that technology leads to economic growth (Solow, 1956; Arrow, 1962) and development of the countries, which is true (Reeves and Harnoss, 2016; Ahmad,2014). As far as globalisation-technology interaction is concerned, there are two schools of thought. One school of thought holds the view that globalisation-technology interaction hampers the development by increasing within-the countries inequality, particularly financial globalisation- FDI is associated with an increase in equalities (Jaumotte et al., 2008; Lee, 2014). Another school of thought holds the view that globalisation-technology interaction leads to development of the countries mainly by reducing the within-the country income-inequalities. Increasing trade and FDI do not emerge as the main culprits of increasing within the country inequality in developing countries and increasing trade seems to foster economic growth and absolute poverty alleviation (Lee and Vivarelli, 2006). We now examine their viewpoints regarding globalisation and technology first at national level and then at global level.

Both globalisation and technology have their own spread and backwash effects. At the national level, the technology remains confined for long period of time. Spread effects of this confined technology are not always greater than its backwash effects and its backwash effects are sometimes greater than its spread effects. This happens due to the confined nature of the technology, as is the case with India. As a result, some regions often lag behind other technology confined regions of the country. As a result there is increase in inequalities but this increase is very low. On the other hand, in case of globalisation, spread effects are often greater than the backwash effects and its backwash effects are generally negligible (i.e. sometimes they may be active and sometimes 
inactive). Whether backwash effects are active or inactive would depend upon the backwash effects of the technology. In general, globalisation leads to decrease in inequalities because globalisation takes place simultaneously in all regions of the country which makes its spread effects stronger than its backwash effects. However, this reduction in inequalities is very low.

Now the question arises what causes extreme increase or decrease in within the country inequalities? The explanation is as follows: Along with globalisation, technology transfer/development also takes place. When in both globalisation and technology combined spread effects are greater than their combined backwash effects then there is within the country reduction in inequalities. Combined spread effects of globalisation and technology become greater than their combined backwash effects only when there is a good interface between globalisation and technology. So in order to reduce within the country inequalities the good interface between globalisation and technology is a sinequa- non. On the other hand, when in technology backwash effects are greater than its spread effects, the backwash effects of globalisation become active and as result the combined backwash effects of globalisation and technology become greater than their combined spread effects. This leads to increase in within the country inequalities. The combined backwash effects of globalisation and technology turn greater than their combined spread effects only when there is a bad interaction and mismangenment between globalisation and technology.

At the global level, technology and globalisation work in a different manner due to the presence of spill over effects of widespread technology. The globalisation supplements the spill over effects of technology at the global level. At the global level, the combined spread effects of globalisation and technology are always greater than their combined backwash effects, at least for two reasons: firstly, the presence of spill over effects of widespread technology and secondly, the backwash effects of globalisation always remains negligible or inactive. Further, here technology does not remain confined but becomes widespread because other countries follow it in swarm like cluster. In simple words, we can say that the spill over effects of the technology and inactive backwash effects of globalisation maintain the proper interaction between the globalisation and technology at the global level. Thus, the net result is that there is reduction of between the countries inequalities.

From the above discussion it follows that the technology and globalisation are two sides of the same coin and that there is nothing bad in technology and globalisation. However, what causes bad view about them is the lack of proper interaction between globalisation and technology and the mismanagement between of the two. So the need of 
the hour is to maintain proper interaction between globalisation and technology so as to reduce inequalities within and across the countries.

Further, the increase in existing literature that holds globalisation responsible for increasing inequalities make the common man feel that globalisation is bad. However, as it becomes obvious from the above discussion, globalisation does not increase inequalities rather it reduces inequalities. The bad view about globalisation and technology is generated by wrong understanding of globalisation in general and globalisation and technology interface in particular.

\subsection{Features of New Globalisation}

- A stretching of economic, social, political, cultural and digital activities across the political frontiers so that happenings and decisions in one region of the world impact people and communities in distant regions of the globe.

- Growing magnitude of interconnectedness in almost every sphere of social existence.

- Local events may come to have serious global consequences and global events can have serious local consequences creating a shared social space. Thus local character of globalisation and global character of globalisation are inter-related.

- The most important feature of new globalisation is Internalisation, Liberalisation and Universalisation (ILU).

- The new contemporary globalisation is 'gauged globalisation' where the participants take into account rational expectations regarding the benefits of globalisation.

- We have moved out of Euro Centric Zone (pole based). Earlier political power was located in one continent of the world. However, now this is not the case. The New Globalisation finds the emergence of the New Power Centers that have destabilising potential.

- In new phase of globalisation, global power shifts which means shift in the global centre of gravity. For example Northern California trades more with rest of Asia Pacific than it does with the rest of North America.

\subsection{Conclusion}

Globalisation is not in retreat but it is different. It is time to recognise this and take action. The winners in the new phase of globalisation will be those who understand the forces of change in a multi polar world and brush up their ideas and notions of 
globalisation. The need of the hour is to understand the interface of globalisation and technology so as to develop a policy paper for developing economies of the world. The emergence of a new model of globalisation does not mean that the old model will suddenly become irrelevant. To succeed in this new era, we need to think about globalisation in a different way, using modern metrics, and devise a new framework to develop winning strategies for participants of globalisation. The contemporary globalisation calls for new methods and measurements. Instead of tracking cross-border flows of physical goods, money, and people, there is a need to measure connected consumers, communities, devices, and machines and to monitor the flow of data and knowledge /ideas. With this we will come up with the better model. In modern times, Greg's 'gated globalisation' has become 'gauged globalisation' because only those gates are opened from which all benefits can be rationally forecasted and then gauged properly by participating players. Thus, national interests dominate the present day globalisation.

\section{References}

Ahmad, A. (2014) Globalisation of science and technology through research and development. Open Journal of Social Sciences, 2(4), 283-287.

Albrow, M. \& Elizabeth, K. (1990). Globalisation, knowledge and society. London: Sage.

Appadurai, A. (1996). Modernity at large: Cultural dimensions of globalisation. Minneapolis, USA: University of Minnesota Press.

Arrow, K. (1962). The economic implications of learning by doing. Economic Studies, 29(3), 155-173.

Beerkens, H. J. J. G. (2004). Global Opportunities and Institutional Embeddedness: Higher education consortia in Europe and Southeast Asia. Netherlands: University of Twente.

Bhattacharya, A., Bürkner, H., \& Bijapurkar, A. (2016). What you need to know about globalisation's radical new phase. Retrieved from Boston Consulting Group website: https://www.bcgperspectives.com/content/articles/globalization-growth-what-needknow-globalization-radical-new-phase/ 
Cox, R. (1994). Global restructuring: Making sense of the changing international political economy. In Richard Stubbs and Geoffrey Underhill (eds.), Political Economy and the Changing Global Order. New York: St. Martin's Press.

Currie, J., \& J, Newson. (1998). Universities and globalisation: Critical perspectives. California: Sage Publications.

Dicken, P. (1998). Global shift. 3rd edition. New York: The Guilford Press.

Featherstone, M. (1995). Undoing culture: Globalisation, postmodernism and identity. London: Sage Publications.

Giddens, A. (1990) .The consequences of modernity. Cambridge: Stanford University Press.

Giddens, A.(1999). Runaway world: How globalisation is reshaping our lives. New York: Routledge.

Gilpin, R. (2001). Global political economy understanding the international economic order. New Jersey: Princeton University Press.

Goodwin, K. D. (2005). Team of rivals: The political genius of Abraham Lincoln. USA: Simon \& Schuster.

Greg,I.P.(2013). The Gated Globe.The Economist. Retrieved from http://www.economist.com/news/special-report/21587384-forward-marchglobalisation-haspaused-financial-crisis-giving-way.

Harvey, D. 1989. The condition of postmodernity. Massachusetts, USA: Blackwell Publishers.

Jaumotte, F., Lall, S., \& Papageorgiou, C. (2013). Rising income inequality: Technology, or trade and financial globalization? IMF Economic Review, 61(2), 271309. 
Lee, E. \& Vivarelli, M. (2006). Understanding globalisation, employment and poverty reduction. New York: Palgrave Macmillan.

Lee, K. (2014). Globalisation, income inequality and poverty: Theory and empirics.Retrieved from http://r-cube.ritsumei.ac.jp/bitstream/10367/5827/1/ BKS28_lee.pdf.

Muth, J. F. (1961). Rational expectations and the theory of price movements. Econometrica, 29(3), 315-335.

Myrdal, G. (1957). Economic theory and undeveloped regions. London: Methuen $\&$ Co.

Reeves, M. \& Harnoss, J. (2017). The business of business is no longer just business: Retrieved from The Boston Consulting Group website: https://www.bcg.com/enin/publications/2017/corporate-strategy-business-no-longer.aspx.

Robertson, R. (1983). Interpreting globality. In World Realities and International Studies Today. Glenside, PA: Pennsylvania Council on International Education.

Sargent, T., \& Wallace, N. (1975). "Rational" expectations, the optimal monetary instrument, and the optimal money supply rule. Journal of Political Economy, 83 (2), $241-254$.

Scholte, J. A. (2000). Globalisation: A critical introduction. London: Palgrave Macmillan.

Scholte, J. A. (2007). Defining globalisation, Clm.economía: revista económica de Castilla - La Mancha, 10, 15-63.

Schreiter, R.J. (1997). The new catholicity: Theology between the global and the local. New York: Orbis Books.

Samuelson, J. (2013).The new globalisation. Retrieved from https://www.washingtonpost.com/opinions/robert-samuelson-the-new-globalization/ 
2013/10/16/d0286c84-3682-11e3-8a0e-4e2cf80831fc_story.html?utm_term=.17fb1920 fed4.

Solow, R.M. (1956). A contribution to the theory of economic growth. The Quarterly Journal of Economics, 70(1), 65-94.

Webster. (1961). Webster's Third New International Dictionary of the English Language Unabridged (Springfield, MA: Merriam). Retrieved from http://wrap.warwick.ac.uk/id/eprint/29130.

World Bank. (2000). Poverty in an age of globalization. Retrieved from http://www1.worldbank.org/economicpolicy/globalization/documents/povertyglo balization.pdf 